\title{
Patients with Alcohol Problems in the Emergency Department, Part 2: Intervention and Referral
}

\author{
GaIl D'ONOFRIO, MD, EDWARD BERNSTEIN, MD, \\ JUDITH BERNSTEIN, PHD, ROBERT H. WOOLARD, MD, \\ Phillip A. Brewer, MD, SANDra A. Craig, MD, BRIAN J. ZinK, MD, \\ FOR THE SAEM SUBSTANCE ABUSE TASK FORCE
}

\begin{abstract}
Early intervention and appropriate referral of patients with alcohol problems have the potential to reduce alcohol-related morbidity and mortality. Part 1 of this series introduced screening tools that can be applied in the ED to allow early detection of at-risk drinkers. This article was developed by members of the SAEM Substance Abuse Task Force and
\end{abstract}

describes assessment and intervention techniques once the at-risk or dependent drinkers has been identified. Appropriate aftercare and referral of patients found to have alcohol problems are also discussed. Key words: alcohol abuse; ED screening; intervention; ED referral. ACADEMIC EMERGENCY MEDICINE 1998; 5:1210-1217

\section{ASSESSING READINESS TO CHANGE}

If the initial assessment of the ED patient reveals a problem with alcohol, then the next step is to gather information concerning the patient's perception of his or her alcohol use, including consequences of drinking, expected results of drinking, and motivation to change. This information will help in making decisions about intervention and referral.

A model of how people change has been developed by psychologists Prochaska and DiClemente. ${ }^{1}$ They have described a series of stages through which people pass in the course of changing behavior (Fig. 1). The circle implies that it is normal for patients to go through the process several times. The first point of entry is the "precontemplation" stage. Here the person is not even aware that a problem exists, or that change is necessary. More often, a significant other or health care provider knows of the person's problem. At this stage

From the Section of Emergency Medicine, Yale University School of Medicine (GD, PAB), New Haven, CT; the Department of Emergency Medicine, Boston University School of Medicine (EB), Moston, MA; the Department of Maternal and Child Health, Boston University School of Public Health (JB), Boston, MA; the Department of Emergency Medicine, Brown University School of Medicine (RHW), Providence, RI; the Department of Emergency Medicine, Carolinas Medical Center, (SAC), Charlotte, NC; and the Section of Emergency Medicine, University of Michigan Medical School (BJZ), Ann Arhor, MI. Received March 10, 1998; revision received July 15, 1998; accepted July 15, 1998.

Address for correspondence and reprints: Gail D'Onofrio, MD. Section of Emergency Medicine, 464 Congress Avenue, New Haven, CT 06519. Fax: 203-785-4580; e-mail: gail. donofrio@yale.edu the person needs information and feedback to raise the possibility that there is a problem that necessitates change. The "contemplation" stage occurs once the person is aware that a problem exists, and is characterized by ambivalence. At this stage there is movement back and forth between reasons for and against change. This is where the brief negotiation interview (BNI) may be most useful to tip the scale toward change. The "preparation" stage is where a provider can assist the person to find a strategy for change that is appropriate for that individual, offering a range of accessible, effective strategies. The "action" stage is where the person participates in specific actions to initiate change. Once a change is made, however, there is no guarantee that it will persist. The "maintenance" stage is focused on the effort to sustain change without relapse.

\section{INTERVENTION}

Brief Interventions. Intervention is defined as "to come between as an influencing force." This is exactly the intention of brief interventions designed to reduce or eliminate the enormous personal and social consequences of alcohol and drug abuse, to stand between the person and the addiction, and to assist the person who has a substance abuse problem to confront the negative consequences of addictive behavior. Unlike treatment systems, which require individuals to self-identify need for treatment and actively seek treatment, these interventions include a detection process, identifying the problem and its consequences, and are designed for use in sites where substance abusers are usually found. 
Brief interventions are short counseling sessions (5-15 minutes), which can be carried out by the emergency physician (EP). Discussion centers around the substance abuse data that the patient has provided, either by self-report, by structured screening question, by observable behavior, i.e., injury while drinking, or by laboratory findings. A recommendation is given to stop using alcohol, and treatment options are offered. Brief interventions involve less time than traditional counseling, are implemented by providers who are not addiction specialists, stress self-responsibility, reach out to substance abusers, and cost less. ${ }^{2-4}$

Bien and Miller, ${ }^{5}$ reviewed 32 controlled trials of brief counseling, and found that not only was brief counseling more effective than no treatment, but it compared favorably with more traditional treatments. A World Health Organization study confirms the positive results of brief intervention in a variety of primary care settings. ${ }^{6}$ Heavy drinkers were evaluated across 12 nations with very different cultural orientations and social circumstances. When simple advice, brief counseling, and extended counseling outcomes were compared with a control group, male drinkers receiving 5 minutes of brief advice reduced their typical alcohol consumption by $21 \%$, and those exposed to a $15-\mathrm{min}$ ute brief intervention reduced their typical daily alcohol consumption by $27 \%$, compared with only $7 \%$ among controls ( $n=1,260$ males). There was a significant effect for all interventions, and 5 minutes of simple advice was as effective as other treatments. Physician warning has been cited as a motivation for entering alcohol treatment. ${ }^{7}$

The earliest randomized trial of a brief intervention was conducted in the Massachusetts General Hospital ED in 1957 by Chafetz and colleagues. ${ }^{8} \mathrm{~A}$ baseline survey found that less than $1 \%$ of 1,200 patients who presented with the diagnosis of alcoholism sought treatment in the institution's alcohol clinic. The intervention involved establishing two teams composed of a psychiatric resident and a psychiatric social worker to work in the then EW (emergency ward). The members were trained to recognize the dependency needs and low selfesteem of the dependent drinker, to reduce frustration, to provide continuity of care, and to communicate through action. They also were trained to make the patient feel welcome and respected, and avoid impersonality, rejection, and hostility. Experimental group patients were referred directly to the resident's clinic, and the social worker provided concrete services such as help with housing, finances, and meals. The results showed that $65 \%$ of the intervention group kept their initial visits to the clinic, compared with $5.4 \%$ of the control group; and $42 \%$ of the experimental group returned to the clinic five or more times, compared

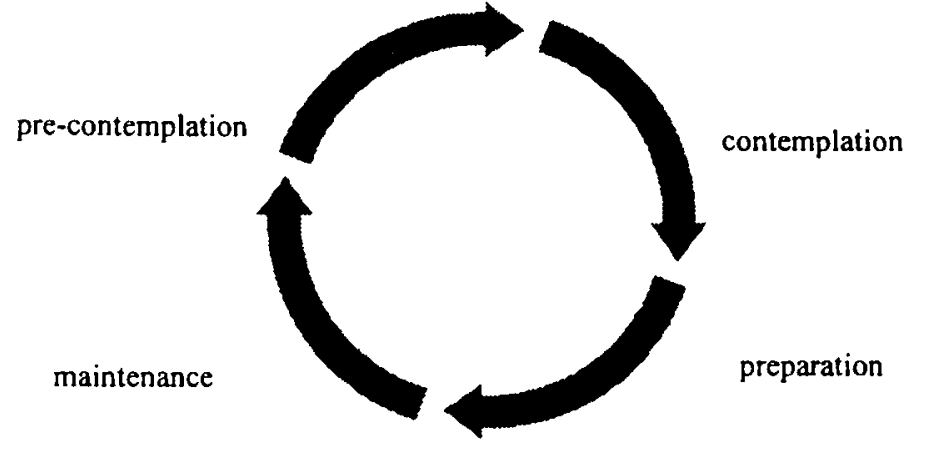

action

Figure 1. Stages of change model. Adapted with permission from: Prochaska J, DiClemente C. The Transtheoretical Approach: Crossing Traditional Boundaries of Therapy. Pacific Grove, CA: Brooks/Cole, 1984, p 30.

with $1.1 \%$ of the control group $(n=200)$. The study demonstrated that despite the fact that the subjects were destitute, middle-aged white men without families, with high incidences of homelessness, isolation, and unemployment, they could form meaningful therapeutic relationships in a userfriendly system.

A randomized, controlled trial of brief intervention in 17 community-based primary care practices involving 64 physicians and 723 subjects in ten Wisconsin counties demonstrated significant reductions in alcohol consumption. ${ }^{9}$ Alcohol use for the experimental group declined from 19.1 mean number of drinks in the previous seven days at baseline to 11.5 at 12 months, compared with 18.9 at baseline and 15.5 at 12 months among the control group. Episodes of binge drinking for the experimental group declined from 5.7 episodes in the prior 30 days at baseline to 3.1 at 12 months, compared with 5.3 at baseline to 4.2 at 12 months for the control group. In addition, the proportion of experimental subjects reporting excessive drinking in the previous seven days declined from $47.5 \%$ at baseline to $17.8 \%$ at 12 months, compared with $48.1 \%$ at baseline to $32.5 \%$ at 12 months for the control group. The intervention protocol consisted of a workbook with information about health behaviors, the prevalence of problem drinking, and the adverse effects of alcohol; a worksheet on drinking cues; a prescription/agreement to address drinking issues; a diary of drinking; two 15-minute visits, a month apart, for brief intervention and reinforcement; and a follow-up phone call.

Project ASSERT at Boston Medical Center has successfully applied the BNI. ${ }^{10}$ Detection, intervention, and referral are performed by trained outreach workers from cultural groupings similar to those of the patients. Of 7,118 adult ED patients screened for alcohol and drug problems, 2,931 were 


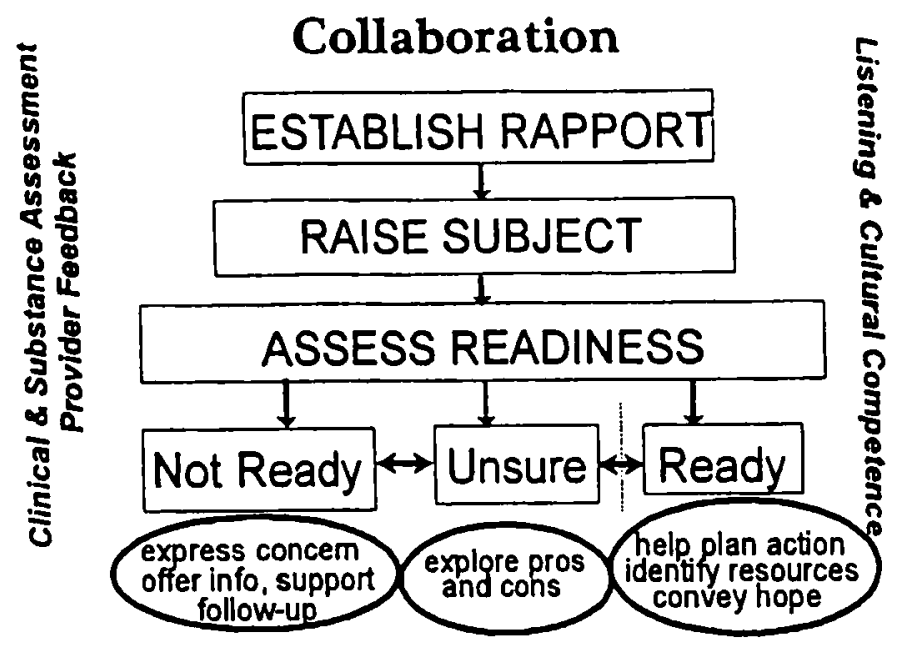

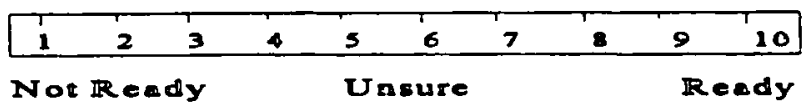

IRIIAIDINIESS IRUILIEIR

Figure 2. Brief Negotiation Interview-algorithm for the ruler concept. Reproduced with permission from: D'Onofrio G, Bernstein E, Rollnick S. Motivating patients for change: a brief strategy for negotiation. In: Bernstein E, Bernstein $\mathrm{J}$ (eds). Case Studies in Emergency Medicine and the Health of the Public. Boston: Jones and Bartlett, 1996, p 301.

detected and 1,096 ED patients were enrolled in the first 12 months. Among the 245 enrollees who participated in a 90-day follow-up, there was a significant reduction in harm at posttest in self-reported behavior, including: a $45 \%$ decrease in drug abuse severity scores, a $67 \%$ reduction in those using cocaine/crack and a $62 \%$ reduction in those using marijuana, a $56 \%$ reduction in alcohol use, and a $64 \%$ reduction in binge drinking. More than $50 \%$ reported following up with the treatment referral. Patients also were linked to primary care and other preventive services. The program's health promotion advocates made 8,848 referrals, and of these, 2,018 patients were referred to the substance abuse treatment system. Treatment options were negotiated with patients, all potential available treatment slots were explored, and once placement was secured, taxicab vouchers were provided to the facilities.

Brief Motivational Interviewing. Motivational interviewing can make brief interventions more effective. The principles of brief motivational interviewing, developed by Miller and Rollnick, ${ }^{11}$ are encapsulated in the FRAMES acronym (feedback, responsibility, advice, menu or choice, empathy, and self-efficacy). This technique also incorporates elements of the Prochaska and DiClemente stages- of-change model discussed above. ${ }^{1}$ Intervention techniques were developed specific to each stage. The provider assists the person to define the problem, identify his or her present stage, and move through the stages of change toward recovery.

Brief Negotiation Interview (BNI). The BNI was developed as an extension of brief motivational interviewing. While brief advice has been helpful in moderating excessive drinking and smoking, a more patient-centered approach was sought to ensure better and longer-lasting outcomes. ${ }^{12}$ The BNI is a strategy to assist patients to recognize and change behaviors that may pose significant risks to health. The goal of the interaction is to facilitate resolution of ambivalence through exploration of conflicting motivation, i.e., the pros and the cons of drug use, and to negotiate possible strategies for change depending on the patient's readiness to change.

The BNI emphasizes respect for patients and provides room for patient choice through joint patient-provider assessment of readiness, and negotiation to establish where the patient perceives himself or herself to be on the readiness-to-change continuum. Rollnick and Bernstein adapted Prochaska and DiClemente's circular stages of change into a linear ruler form. ${ }^{2}$ An algorithm for use of the ruler concept was then developed by Bernstein and Rollnick and applied to the emergency patient encounter (Fig. 2).

In this model, the patient identifies the problem and generates an array of treatment options. The BNI is not viewed as treatment in and of itself, but as a step in the process of making contact with the treatment system. Through negotiation, patients' needs are tailored to solutions, and patients are matched with treatment modalities that they are able to accept. Information is patient-centered, permitting freedom of choice, and not advice-giving. ${ }^{13,24}$ The physician cannot persuade the patient to change, as in "if you don't ... this may happen," a style that will surely elicit the "yes, but...." response. Central to the success of the BNI is the belief that the patient possesses a unique store of knowledge, his or her own life history, that is essential for behavioral change to occur. The patient's contribution is just as important for achieving the goal of lifestyle change as is the physician's expertise. ${ }^{15}$ With this outlook, the physician-patient encounter is transformed into "a meeting between experts."

Using the BNI in the ED. Table 1 presents the basic steps in the brief negotiation interview process. It describes appropriate goals for the practitioner, and lists some open-ended questions that can be used to elicit information and move the interaction forward. Major concepts include: 
1. Establish rapport with the patient.

2. Ask the patient's permission to discuss the pros and cons of alcohol use.

3. Let the patient self-identify the existence of a problem.

4. Have the patient assess his or her readiness to change (ready, unsure, or not ready).

5. Negotiate a strategy for change, based on the patient's own perception of readiness to change.

If the patient is in the "ready" stage, then the interviewer solicits previous experience in attempting to quit, and the two brainstorm alternatives. If the patient is "unsure," then further assessment may be proposed. If the patient is "not ready," then the interviewer expresses concern and offers information about sources of help available.

General principles for negotiating behavior change are listed in Table 2. Table 3 illustrates some dangerous assumptions about behavior change that should be avoided. Too often the interaction between physician and patient in the ED falls into one of several "traps." An interaction may go as follows:

Doctor: You have had a serious car crash. You're lucky you didn't kill yourself, or anyone else. What do you intend to do about your drinking problem?

Patient: What drinking problem? I had a couple of beers, that's all.

Doctor: Your alcohol level was 190. Clearly you had more than a few beers. So how much do you really drink each day?

Patient: Look, I had a few beers with my buddies after work, what's the big deal? Everyone does. I work hard, and having a drink or two helps me relax after a rough day. Only this time I got a little careless is all. So don't make a big deal of nothing. Just finish sewing me up so I can go. I have to be at work in a few hours.

TABLE 1. The BNI*
Tasks
Groals

To understand patient's concerns and circumstances; to explain provider's role; to avoid a judgmental stance.

Raise subject

Assess readiness

To evaluate readiness to accept a referral.

Provide feedback

To raise patient awareness of the medical aspects of alcohol and drug use and consequences of further use; to let patient know provider's concerns.

Readiness ruler Not ready

To offer further contact if the patient desires; to offer to present your feedback and concerns if the patient wants; to offer referral options.

Unsure

To facilitate the patient's ability to name the problem by discussing pros and cons of use; to understand ambivalence and how to work with it.

Ready
To help patients name solutions for themselves, choose a course of action, and decide how to achieve it; to encourage patient choice.
Questions

Sit down on a chair at bedside and ask open-ended questions that show concern for patient as a person, i.e., "How are you feeling today? Are you comfortable? If I could see the situation through your eyes, what would I see? Help me to understand."

"Would you mind spending 5 minutes talking about your use of your health?"

"How do you feel about your use of ready are you to change your use of ? How (Use ruler).

"How much do you know about what caused the reason for your ED visit? What do you make of all this?"

"Is there anything you would want to know about _-? Would you mind if I tell you about my concerns for your health? What would it take to get you to consider thinking about a change? If you ever decide to stop, what would you do?"

"What are the good things you like about or what it does for you? What are the not so good things/things you don't like about ___? What concerns do you have about your use of __??"

1. Emphasize: a) there are many options; b) you know what has worked for you in the past and for other people; c) you are the best judge of what suits you and can work for you.

2. List option.

3. Ask, "What will work for you?"

4. Offer back-up support and referral.

*Reproduced with permission from: D'Onofrio G, Bernstein E, Rollnick S. Motivating patients for change: a brief strategy for negotiation. In: Bernstein E, Bernstein J (eds). Case Studies in Emergency Medicine and the Health of the Public. Boston: Jones and Bartlett, 1996, p 299. 
TABLE 2. General Principles for Negotiating Behavior Change*

- Respect for autonomy of patients and their choices.

- Readiness to change must be taken into account.

- Ambivalence is common - it needs to be understood.

- Targets need to be selected by the patient, not the expert.

- The expert is the provider of the information and support.

- The patient is the active decision maker.

*Reproduced with permission from: D'Onofrio G, Bernstein E, Rollnick S. Motivating patients for change: a brief strategy for negotiation. In: Bernstein E, Bernstein J (eds). Case Studies in Emergency Medicine and the Health of the Public. Boston: Jones and Bartlett, 1996, p 300.

This interaction demonstrates some common "traps" encountered in counseling. ${ }^{11}$ In this scenario the physician is using authority to shame the patient into a behavior change. In this example of the expert trap, the physician appears to have all the answers, and the patient is placed in the passive role, negating the importance of eliciting the patient's own motivation for change. The heavyhandedness and one-sidedness of this approach may actually increase the patient's resistance to change. The first interactions of the physician are extremely important, as they set the tone for the entire encounter. By telling the patient he has a drinking problem, the physician fell into the confrontation-denial trap. The patient predictably denied the problem and therefore any necessity for change. The physician will then end up arguing one side and the patient, feeling trapped, will defend his behavior.

One also should avoid the labeling trap. "You are an alcoholic." The physician appears judgmental. A struggle for control can ensure with the patient. Additional traps to avoid include the blaming trap, which implies that the problem is someone or something's fault. Time and effort are displaced on finding fault, and the patient becomes defensive. Instead, one needs to focus on the patient's own concerns and what the patient wants to do about them.

Early in the interaction the physician should attempt to avoid the question-answer trap. Here one elicits short, one- or two-word answers on the part of the patient. While this may be necessary during an initial history and physical assessment, it should be avoided once the provider begins to enter into counseling. With monosyllabic responses the patient assumes a passive role and does not make self-motivational comments.

Finally, one of the most difficult challenges for the EP is to avoid the premature focus trap. The physician has a limited time for each patient interaction, and needs to proceed expediently, while the patient may have larger issues and problems. To avoid a struggle, one must allow enough time to focus on the patient's concerns. Sometimes this is just providing a drink of water, offering a phone call to a significant other, or alleviating anxieties about finding a way home.

A second scenario demonstrates the principles of reflective listening and the use of open-ended questions to encourage the patient to communicate ${ }^{11}$ :

Doctor: You had a serious car crash. Do you remember what happened?

Patient: Not really. The last thing I remember is leaving the bar, and the rest is pretty much a blur.

Doctor: You mean you're unable to remember your injury because of your drinking in the bar.

Patient: Yeah, I guess so.

Doctor: That must have been frightening. Would you mind spending a few minutes talking about your drinking?

Patient: My drinking? What about it?

Doctor: What do you enjoy about it?

Patient: Look, I work hard all day, and it helps me relax. My friends and I hang out at the bar a lot.

Doctor: It's a way of relaxing and enjoying being with your friends.

Patient: Yeah.

Doctor: I can understand that everybody needs to unwind. Now are there any things that are not so good about your drinking?

Patient: Not really. Well, I do have trouble getting up in the morning, though. Some days I can't think quite straight in the morning.

Doctor: And that doesn't seem right to you. It must make work more difficult.

Patient: Yeah, the day starts real hard, but I stick it out.

Doctor: Sounds tough. Can you think of any other drawbacks to your drinking?

Patient: Hey, wrecking my car is a drag. I really need that car. And having to be stitched up like this isn't too much fun.

Doctor: No, I imagine not. So, on the one hand, drinking relaxes you and you enjoy doing it with your friends. On the other hand, it makes getting up in the morning more difficult. Wrecking your car and getting sutures are also painful consequences. So where does that leave you?

Patient: I suppose I could cut back some on the drinking, especially during the week.

Doctor: I think that sounds like a terrific idea. Have you ever cut back before?

Patient: Yeah, I've done it before. I can do it on my own.

Doctor: Some people can do it on their own, but for some people it turns out to be difficult. We think that drinking more than 14 drinks per week or more than 4 drinks on any one occasion may put you at risk for illness and injury. If you find that after four weeks you're drinking more than that, in my medical opinion you could benefit from some outside help. I can give you the names and phone numbers of some people who would be happy to speak with you.

Patient: OK, that sounds good. 
Doctor: Now what about your drinking and driving?

Patient: Yeah, that's not a good idea. I'll find someone sober to drive next time, or I guess I could take the bus.

Doctor: That's a great plan.

Patient: Hey, thanks for your help.

In this scenario, an opportunity is provided to explore the connection between drinking and injury with the patient. Reflective listening is a way in which to check what the person meant by a statement. The provider who is nonjudgmental is less likely to elicit resistance and more likely to encourage further thought and reflection on the part of the patient. Reflective listening takes into account what the speaker meant, what the speaker said, what the listener heard, and, finally, what the listener thought the speaker meant. Intonation in reflective-listening statements should usually turn down at the end of the remark to encourage the patient to respond. An upward intonation should be avoided, because it can suggest a challenge or threat.

If the patient is not ready to change, the physician can express concern and offer referral information for the future. If the patient is ready to change, the physician assists the patient to find the best solution, and an appropriate course is identified. The physician may be mandated to report certain behaviors or compelled by professional and/or ethical standards to give written and verbal discharge instructions regarding high-risk behavior, i.e., "Do not drink and drive."

Figure 3 depicts an algorithm for the detection and intervention of problem drinkers in the ED. If the diagnosis of problem drinker is obvious, the EP can proceed directly to asking permission to raise the subject, exploring the pros and cons, assessing readiness, and intervening appropriately. Asking quantity and frequency questions during the negotiation process may lead to resistance and delay or impede negotiation for changing behavior. If at any time the diagnosis is unclear, or the EP is universally screening all patients, one may use the CAGE, or quantity/frequency questions early on in the algorithm, i.e., while eliciting the past medical history.

\section{REFERRAL}

As with any other disorder, referral for further evaluation and treatment of alcoholism are often the most appropriate disposition for the emergency patient. Research has demonstrated clearly that treatment is effective at all stages of the disease process. ${ }^{16}$ Unfortunately, appropriate referral for this problem is often neglected at the time of discharge. In one study of a cohort of 16 chronic, recidivist alcoholic persons, one individual had 300
TABLE 3. Dangerous Assumptions Regarding Behavior Change*

- This person ought to change.

- This person is ready to change.

- This person's health is a prime motivating factor for him or her.

- If he or she does not decide to change his or her behavior, the consultation has failed.

- Patients are either motivated to change, or not.

- Now is the right time to consider change.

- A tough approach is always best.

- I'm the expert-he or she must follow my advice.

*Reproduced with permission from: D'Onofrio G, Bernstein E, Rollnick S. Motivating patients for change: a brief strategy for negotiation. In: Bernstein $E$, Bernstein $J$ (eds). Case Studies in Emergency Medicine and the Health of the Public. Boston: Jones and Bartlett, 1996, p 301.

ED visits over a two-and-a-half-year period and yet was referred for treatment only three times. Three other individuals with a combined total of $152 \mathrm{ED}$ visits received no referrals. ${ }^{17}$ Given the high mortality and morbidity associated with chronic alcoholism, such an approach is unacceptable.

To ensure that each identified patient is given an appropriate disposition, a referral system must be developed for each ED. Without such a system, screening patients for alcohol and substance abuse is an enigmatic process at best. Identifying a problem is of little use unless the means necessary to address it are readily available. Therefore, it is incumbent upon each ED to have a working, userfriendly referral system. A method to develop such a system is outlined below:

An ED list of local resources available for alcohol treatment should include both public and private facilities, detoxification sites, hospital-based treatment programs, community outpatient treatment programs, community physicians knowledgeable about addiction, locations and times of Alcoholics Anonymous (AA) meetings, a list of available AA sponsors, and at least one site that addresses the special problems of women with high-risk drinking. Attention must be paid, when making referrals, to issues of culture and language. This list should be updated regularly and should be immediately available at all times in the ED. It may be edited into a brochure, which can be given to patients with high-risk drinking. Each type of service should be described, including financial and other limitations and restrictions for each program.

Patients enrolled in managed care organizations can be referred directly by the patient's primary care provider. This is usually required for payment to be authorized. Social service or other staff, when possible, should actively assist patients in making contact with the treatment system and arrange for transportation as needed. Direct referral may increase the likelihood that the patient will actually present for treatment. 


\section{ESTABLISH RAPPORT}

\section{RAISE THE SUBJECT}

Do you drink beer, wine or liquor now and then?

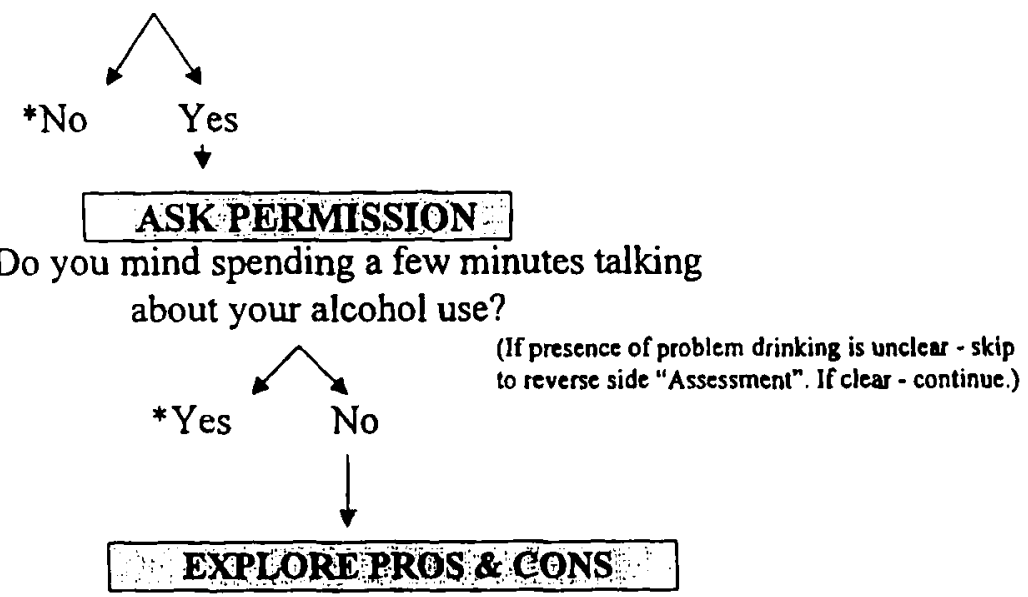

What are some of the good things about drinking for you?

What are the not so good things about your drinking?

Offer Feedback $\longrightarrow$ Do you see a connection between your ED visit today and your drinking?

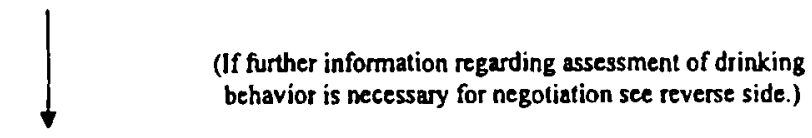

\section{ASSESSREADINESS}

Summarize pros and cons then ask...

Where does this leave you?

Or

How ready are you to change your drinking behavior?

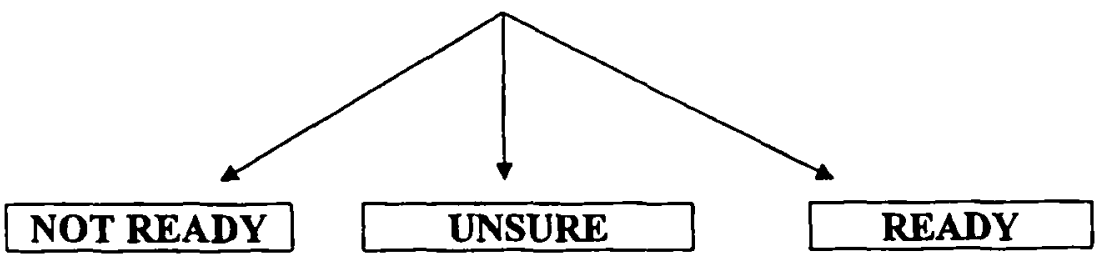

1. Express Concern

1. Ask what will it

1. Help patient

2. Offer education and take to get you ready? Identify resources.

Information for 2. Same as "Not Ready" follow-up (including

2. Make an appropriate referral for treatment. appropriate written instructions, i.e. "Do not drink and drive"). A further attempt at negoliation may be warranted prior to discharge.

Flgure 3 (above and facing column). Algorithm for detection and intervention of problem drinkers in the EDBrief Negotiation Interview (BNI). Questions from: The Physician's Guide to Helping Patients with Alcohol Problems. National Institute on Alcohol Abuse and Alcoholism, NIH Publication No. 95-3769, 1995. 
(If screening patients without evidence of alcohol-related

illness or injury one may start here after asking permission.)

CAGE (in the last 12 months)

1. Have you ever felt you should cut down on your drinking?

2. Have people annoyed you by criticizing

3. Have you ever felt bad or guilty about your drinking?

4. Have you ever had a drink first thing in the morning to "steady your nerves" or get rid of a hangover "eye opener"?

\section{CONSUMPTION}

1. On average, how many days per week do you drink alcohol?

2. On a typical day when you drink, how many drinks do you have?

3. What is the maximum number of drinks you had on any given occasion during the last month?
No

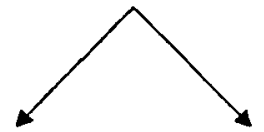

Intervention
If (1) CAGE (+) or

$>14$ drinks per week or

$>4$ drinks per occasion (Men)

$>7$ drinks per week or

$>3$ drinks per occasion

(Women and all over 65)
Continue with exploring Pros \& Cons

or Assessing Readiness to change

if appropriate.

\section{Figure 3 (cont.).}

The patient diagnosed as having an alcohol or drug problem who does not wish to seek care or wish for immediate referral should be given a brochure about treatment options in case he or she decides to seek care at a later time.

A policy regarding referrals should be developed for each ED, stipulating who is responsible for maintaining the list of resources, and how responsibility for referrals is to be shared by the medical, nursing, and social services staffs. Staff in-service on referral policies and procedures for detection, intervention, and referral should be required, and a continuous quality improvement process should be instituted for monitoring compliance and outcomes.

\section{CONCLUSION}

Interventional strategies proven to be effective can then be negotiated with the patient depending on his or her level of need and readiness to change. The BNI is a brief counseling method that can be learned rapidly by EPs, and applied even in the busiest of EDs, with a variety of populations from adolescents to elders. Many EPs are unaware that a brief intervention may trigger a positive change in behavior or encourage patients to seek further treatment. Early referral and treatment may have a dramatic effect for an individual patient and avert major consequences for society.

\section{References}

1. Prochaska J, DiClemente $C$. Toward a comprehensive model of change. In: Miller WR, Heather N (eds). Treating Addictive Behaviors: Processes of Change. New York: Plenum, 1986.

2. D'Onofrio G, Bernstein E, Rollnick S. Motivating patients for change: a brief strategy for negotiation. In: Bernstein $\mathrm{E}$, Bernstein $\mathrm{J}$ (eds). Case studies in Emergency Medicine and the Health of The Public. Boston: Jones and Bartlett, 1996, pp 295-303.

3. Fuller RK, Perl HI. Screening and treating alcohol problems in primary care medical setting. Frontlines. 1996; Nov:1-2.

4. Heather N. Psychology and brief intervention. Br J Addiction. $1989 ; 84: 357-70$.

5. Bien T, Miller WR. Brief interventions for alcohol problems: a review. Addiction. 1993; 88:315-36.

6. World Health Organization Brief Intervention Study Group. A cross national trial of brief interventions with heavy drinkers. Am J Public Health. 1996; 86:948-55.

7. Walsh D, Hingson RW, Merrigan DM, et al. The impact of a physician's warning on recovery after alcoholism treatment. JAMA. 1992; 267:663-7.

8. Chafetz ME, Blane HT, Abram HS, et al. Establishing treatment relations with alcoholics. J Nerv Ment Dis. 1962; 134: $395-409$

9. Fleming MF, Barry KL, Manwill LB, et al. Brief physician advice for problem drinkers: a randomized controlled trial in community based primary care practices. JAMA. 1997; 25:5271.

10. Bernstein E, Bernstein J, Levenson S. Project ASSERT: an ED based intervention to increase access to primary care, preventive services, and the substance abuse treatment system. Ann Emerg Med. 1997; 30:181-9.

11. Miller WR, Rollnick S. Motivational Interviewing: Preparing People to Change Addictive Behavior. New York: Builford, 1991 .

12. Ockene J, Kristeller J, Goldberg $R$, et al. Increasing the efficacy of physician-delivered smoking interventions. A randomized clinical trial. J Gen Intern Med. 1991; 6:1-8.

13. Roter DL, Hall JA, Katz NR. Physician-patient communication: a descriptive summary of the literature. Pat Educ Counseling. 1988; 12:99-119.

14. Stewart M, Roter D. Communicating with Medical Patients. London: Sage, 1989.

15. Tuckett D, Boulton M, Olson C, Williams A. Meetings between experts. New York: Tavistock Publication, 1985.

16. Miller WR. The effectiveness of treatment for substance abuse: reasons for optimism. J Subst Abuse Treat. 1992; 9:93102.

17. Saadi H, Brewer PA, Degutis L, Patton CL. Cluster pattern of presentation in high frequency emergency department patients with ethanol intoxication [abstract]. Ann Emerg Med. $1996 ; 27: 142$. 